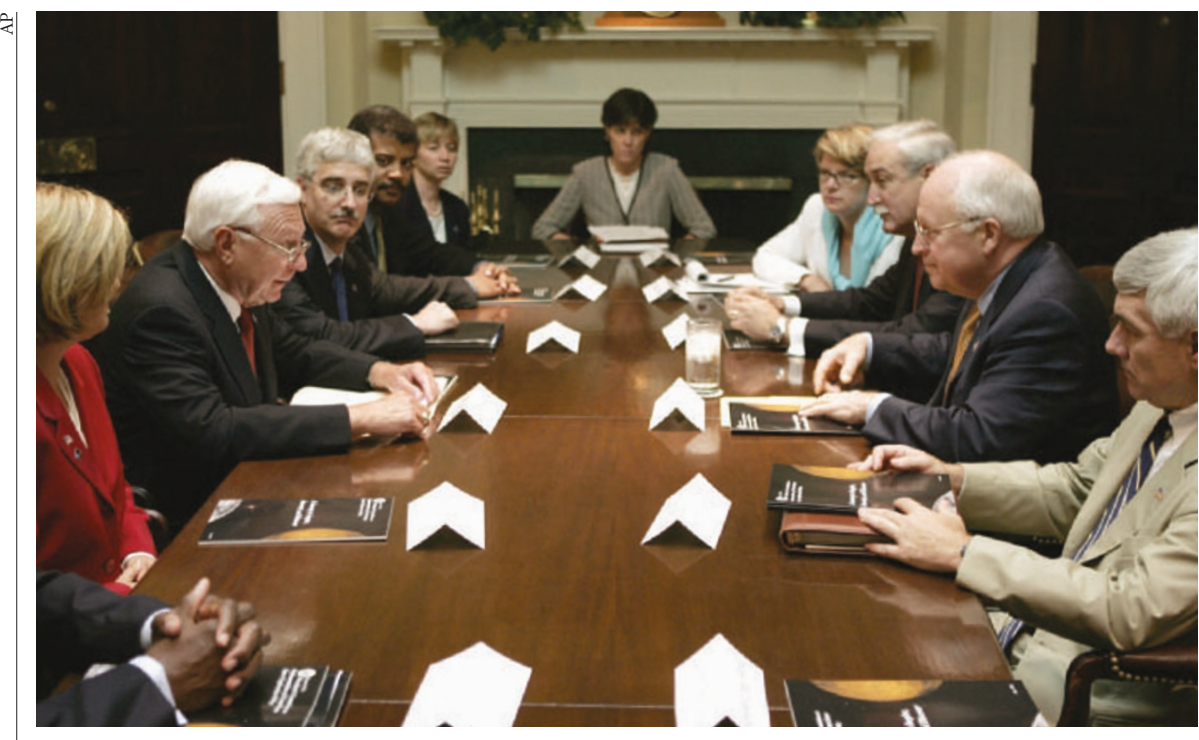

Mission commission: Bush's panel recommends turning NASA labs into federally funded centres.

\section{NASA reforms needed to give Moon-Mars plan a better shot}

Tony Reichhardt, Washington

President Bush's ambitious plan to send astronauts to the Moon and Mars will only get off the ground if NASA centres are run differently, says a commission appointed to look into the plan's execution.

On 16 June, the presidential commission published a report calling on NASA to give private contractors or universities the management of its network of ten major space centres, such as the Goddard Space Flight Center in Maryland.

But critics say that the idea faces political obstacles that could doom it from the start. Plans to involve the private sector more deeply in manned space flight amount to little more than wishful thinking, they charge despite this week's independent foray into space (see opposite page).

Bush laid out his plan in January (see Nature, 427, 183; 2004) and asked the panel, led by former US Air Force secretary Edward 'Pete' Aldridge, to determine how it might be carried out. The commission's report supports Bush's goal of sending humans beyond Earth orbit, but says that "the infrastructure of NASA is too large".

The panel had considered how to shut down some of the centres and Senator Sam Brownback (Republican, Kansas), who chairs the Senate subcommittee that oversees NASA, expressed interest in a law that would pave the way for such closures.

But Aldridge says politicians from states with NASA centres would almost certainly have blocked such a move. "Our report would probably have been burned on the first day," if it had taken that approach, he told a Senate hearing on 17 June.
Instead, the commission recommended that NASA convert its centres to Federally Funded Research and Development Centers (FFRDCs), like its Jet Propulsion Laboratory in Pasadena, California. The scientists and engineers at such centres are employees of universities or industrial companies, rather than civil servants.

But Paul Light, who studies federal workforce issues at the Brookings Institution in Washington, doubts that this would work for most NASA centres. "There's no magic in conversion to FFRDC status," he says. Light adds that the concept is sometimes just a ruse to move civil servants off the federal payroll without actually reducing costs or employee numbers.

And Marc Cohen, a space project planner and head of the union of scientists and engineers at NASA's Ames Research Center in California, warns that NASA scientists could fare badly under such a plan. He says it would favour centres that can do contract engineering work. "Most of us work very far away from the marketplace," Cohen says.

The Aldridge commission also said that "an independent space industry does not really exist" in the United States yet, and that the private sector was unlikely to put money into a Moon-Mars programme. But it added that there were steps that NASA could take to promote independent investment, such as offering cash prizes to innovators.

Senator Brownback agrees: a NASA authorization bill he introduced last week would give an award to the first outside group to put a person into orbit, and would call for the agency's next robotic lunar mission to be privately operated.

\section{British drug company to put data online as criticism mounts}

Jim Giles, London

Things are hotting up for Britain's largest drugs firm, GlaxoSmithKline (GSK), in the wake of a legal challenge launched earlier this month by Eliot Spitzer, New York state's attorney-general.

On 18 June, the British parliament announced an investigation into the pharmaceutical industry. On the same day, London-based GSK said that it would make all clinical trial data for marketed drugs available online to the public. But two days later, British lawyers representing patient groups announced fresh legal action against GSK.

The company's online data registry, due to launch later this year, will include summaries of trial protocols and data for everything from initial toxicology and safety studies to trials run on drugs after they have been licensed. "All the important results will be there," says GSK spokesman David Mawdsley.

Results from one such post-licensing trial are important to Spitzer's case. The attorney-general alleges that GSK failed to disclose data showing that the antidepressant paroxetine, known as Paxil in the United States and Seroxat in Britain, is no more effective than a placebo for depressed young people and might even increase the risk of suicide in this group (see Nature 429, 589; 2004). The drug has been approved by US regulators for use in adults, but it is frequently prescribed to under-18s.

Mawdsley says they have been considering the registry for a while: "This is going to be a big job. We started discussing it well before the Spitzer case."

GSK is also expected to hear shortly from Hugh James, a Cardiff law firm which says it is acting on behalf of 3,500 patients who claim to have suffered withdrawal symptoms when coming off Seroxat. The company, which says it is also representing relatives of "a few tens" of people who committed suicide while on the same drug, say they will outline their claim in a letter to GSK in the next few weeks. GSK declined to comment.

Later this year, the drug manufacturer may have to defend itself on a third front, when the House of Commons opens an inquiry into the pharmaceutical industry. The wide-ranging investigation, due to begin in September, will look at the influence of the industry on medical research, the promotion of drugs and regulatory reviews of drug safety and efficacy. 